\title{
Inhibition by PGI-2 of myometrial activity in vivo in non-pregnant ovariectomized sheep
}

\author{
S. J. Lye and J. R. G. Challis \\ The University of Western Ontario, MRC Group in Reproductive Biology, Departments of \\ Obstetrics \& Gynaecology and Physiology, London, Ontario, Canada N6A 5A5
}

\begin{abstract}
Summary. The effects of PGI-salt and PGI-2 methyl ester on intrauterine pressure (IUP) and uterine electromyographic activity (EMG) were examined in vivo in non-pregnant ovariectomized sheep. PGI-2 salt and PGI-2 methyl ester (50-200 $\mu \mathrm{g})$ reduced significantly the frequency and amplitude of IUP cycles and also inhibited the associated uterine EMG activity. Injections of oxytocin $(50 \mathrm{mU})$ or PGF- $2 \alpha$ $(2 \mu \mathrm{g})$ partly overcame the inhibition of IUP induced by the PGI-2 methyl ester. These results suggest that endogenous PGI-2 may be involved in the regulation of uterine activity in sheep.
\end{abstract}

\section{Introduction}

Prostacyclin (PGI-2) is a potent inhibitor of platelet aggregation and it relaxes vascular smooth muscle (Moncada, Gryglewski, Bunting \& Vane, 1976; Armstrong, Dusting, Moncada \& Vane, 1978). Several investigators have shown that PGI-2 is present in the myometrium of pregnant and non-pregnant animals and in women (Jones, Poyser \& Wilson, 1977; Williams, Dembinska-kiec, Zmuda \& Gryglewski, 1978; Omini, Folco, Pasargiklian, Fano \& Berti, 1979). PGI-2 is also produced in the human placenta (Myatt \& Elder, 1977) and in the fetal membranes (Satoh et al., 1981). PGI-2 may be involved in the inhibition of uterine activity during pregnancy (Thorburn \& Challis, 1979), but in-vitro experiments have provided conflicting results. Omini, Pasargiklian, Folco, Fano \& Berti (1978) showed that PGI-2 inhibited spontaneous and PGF-2 $\alpha$ induced contractile activity in strips of human myometrium in vitro and this inhibition was correlated (Omini et al., 1979) with an increase in the accumulation of cyclic AMP in the tissues. In contrast Williams, El-Tahir \& Marcinkiewicz (1979) demonstrated that, in the rat, PGI-2 stimulated myometrial activity in vitro. In view of this apparent conflict we have examined the effects of PGI-2 on the mechanical and electrical activity of the sheep uterus, but using in-vivo procedures.

\section{Materials and Methods}

At laparotomy under general anaesthesia 4 non-pregnant sheep were bilaterally ovariectomized. Recording balloons were placed in the uterine lumen (Lye \& Porter, 1978), and 3 pairs of stainless steel electrodes (Cooner Corp., California, U.S.A.) were sutured into the myometrium at the tubal, middle and cervical regions of one uterine horn. A femoral artery and femoral vein were catheterized using vinyl tubing (Bolab, Arizona, U.S.A.; Manchester, Challis, MacLennan, Patrick \& Workewych, 1980). The femoral arterial catheter was fed $20 \mathrm{~cm}$ into the vessel such 
that its tip lay in the abdominal aorta $6-10 \mathrm{~cm}$ above the origin of the uterine artery. The animals received $50 \mu \mathrm{g}$ oestradiol-17 $\beta$ s.c. for 5 days after surgery. Oestradiol was then withdrawn to establish a pattern of continuous spontaneous activity (Porter, 1979).

Solutions of PGI-2 methyl ester and PGI-2 sodium salt (Upjohn Co., Toronto, Ontario) were prepared fresh on the day of use by dissolving the dry material in a 1:1 solution of ethanol :bicarbonate buffer $(0.1 \mathrm{M} ; \mathrm{pH} 9.5 ; \mathrm{v} / \mathrm{v})$. The stock solutions stood on ice until use, when an aliquant $(0.1 \mathrm{ml})$ containing 50,100 or $200 \mu \mathrm{g}$ PGI- 2 was added to $5 \mathrm{ml}$ saline $(9 \mathrm{~g} \mathrm{NaCl} / \mathrm{l})$. Within $30 \mathrm{sec}$ of dilution the material was injected through the femoral arterial catheter over a period of $90 \mathrm{sec}$. Synthetic oxytocin $(50 \mathrm{mU} / 0.25 \mathrm{ml}$ saline; Armitage Carroll, London, Ontario, Canada) or PGF- $2 \alpha(2 \mu \mathrm{g} / 0.2 \mathrm{ml}$ saline; Lutalyse: Upjohn) were administered through the femoral arterial catheter. The frequency and maximum amplitude of intrauterine pressure cycles were analysed in 5-min periods as described previously (Lye \& Porter, 1978). Results are expressed as mean \pm s.e.m. for 4 sheep. The effects of PGI-2 on uterine activity were assessed using Duncan's multiple range test (Snedecor, 1956).

\section{Results}

Text-figure 1 shows a representative trace of the effects of PGI-2 methyl ester $(200 \mu \mathrm{g})$ on uterine mechanical and electrical activity in one of the sheep. There was a transient increase in resting pressure and in amplitude of intrauterine pressure cycles in the 2-3 min after the injection. There was then a complete cessation of electromyographic and intrauterine pressure

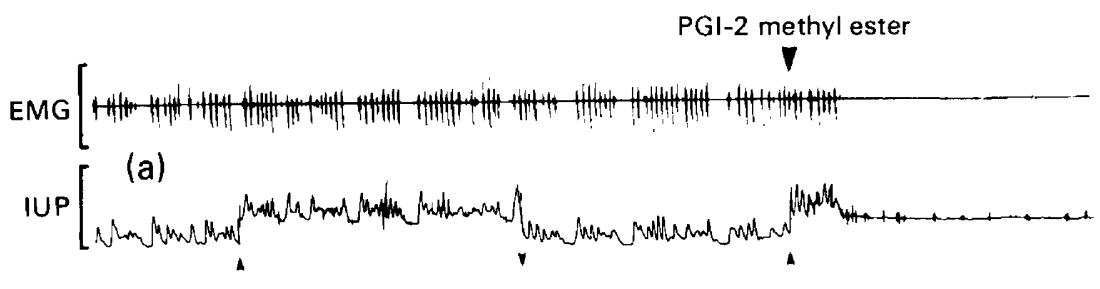

EMG

(b)
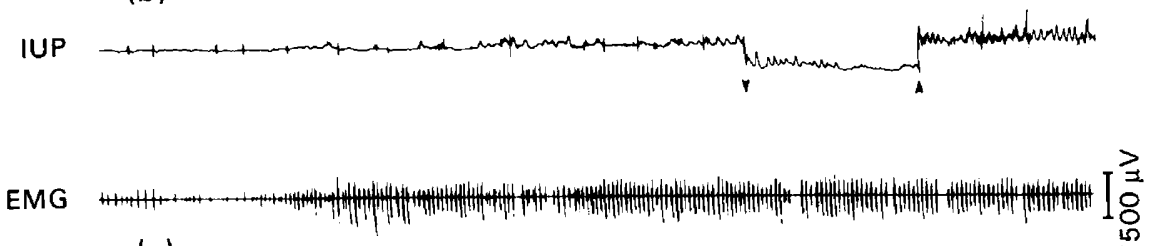

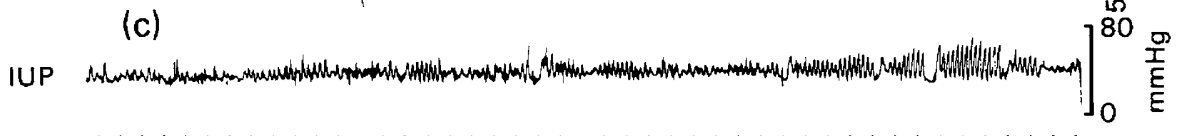

Minutes

Text-fig. 1. Continuous recordings of electromyographic activity (EMG) and intrauterine pressure (IUP) traces from one sheep during a period of $35 \mathrm{~min}$ before to $100 \mathrm{~min}$ after injection of $200 \mu \mathrm{g}$ PGI-2 methyl ester into the femoral artery catheter. For clarity only 1 of the $3 \mathrm{EMG}$ records is shown; the other 2 traces were similar. Each pair of EMG and IUP records $(a, b, c)$ represents a 45-min recording interval. Small arrows indicate times when the animal stood $(\Delta)$ or lay down ( $\mathbf{\nabla})$. Within 2-3 min of PGI-2 injection there was a complete loss of IUP and EMG activity. 

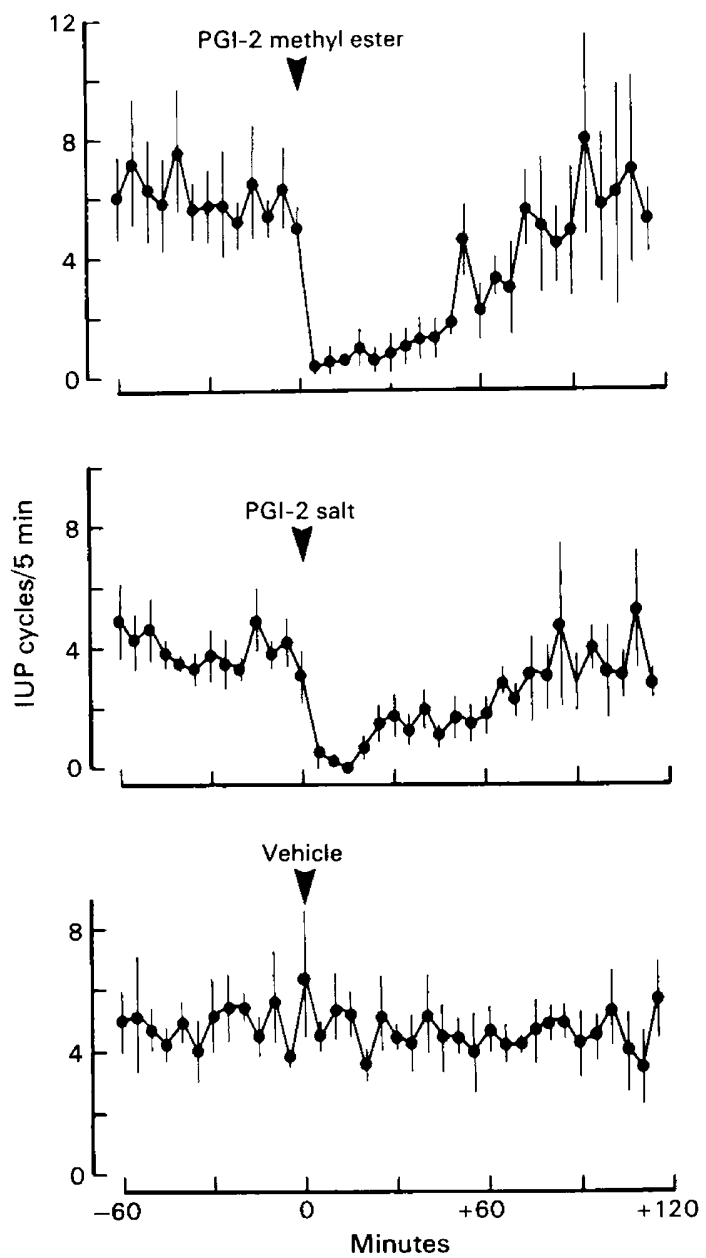

Text-fig. 2. Frequency (mean \pm s.e.m. for 4 sheep) of intrauterine pressure cycles during 60 min before until $120 \mathrm{~min}$ after administration of PGI-2 methyl ester or PGI-2 salt (both $200 \mu \mathrm{g}$ ) or vehicle into the femoral artery catheter of non-pregnant ovariectomized sheep.

activity which lasted for about $45 \mathrm{~min}$. Both activities slowly returned, with full recovery occurring approximately $90 \mathrm{~min}$ after the PG administration. The results for all 4 animals are presented in Text-fig. 2. There was a rapid and significant inhibition of the frequency of intrauterine pressure cycles after injection of both preparations of PGI-2: values (mean \pm s.e.m.) fell from $6.1 \pm 0.4$ and $4.0 \pm 0.23$ cycles $/ 5 \mathrm{~min}$ before injection to $0.25 \pm 0.25$ and $0.5 \pm 0.5$ cycles $/ 5$ min at 5 min after PGI-2 methyl ester and PGI-2 salt respectively (both $P<0.001$ ), and remained significantly below preinjection values for about $60 \mathrm{~min}(P<0.05)$. The mean maximum amplitude of intrauterine pressure cycles fell from preinjection values of $35.6 \pm 1.9$ and $27.3 \pm 1.3 \mathrm{mmHg}$ to $2.8 \pm 2.8$ and $4.0 \pm 4.0 \mathrm{mmHg}$ at $5 \mathrm{~min}$ after PGI-2 methyl ester and PGI-2 salt respectively (both $P<0.001$ ). Injection of the methyl ester at the lower dosages of 50 and $100 \mu \mathrm{g}$ also caused an inhibition of spontaneous uterine activity, but of shorter duration. There was no change in the frequency or maximum amplitude of intrauterine pressure cycles after injection of vehicle alone (Text-fig. 2). Oxytocin and PGF-2 $\alpha$ were injected at 15 min after 
(a)

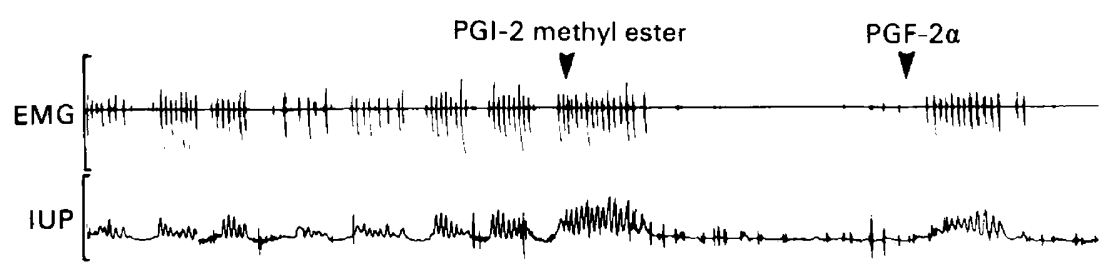

(b)

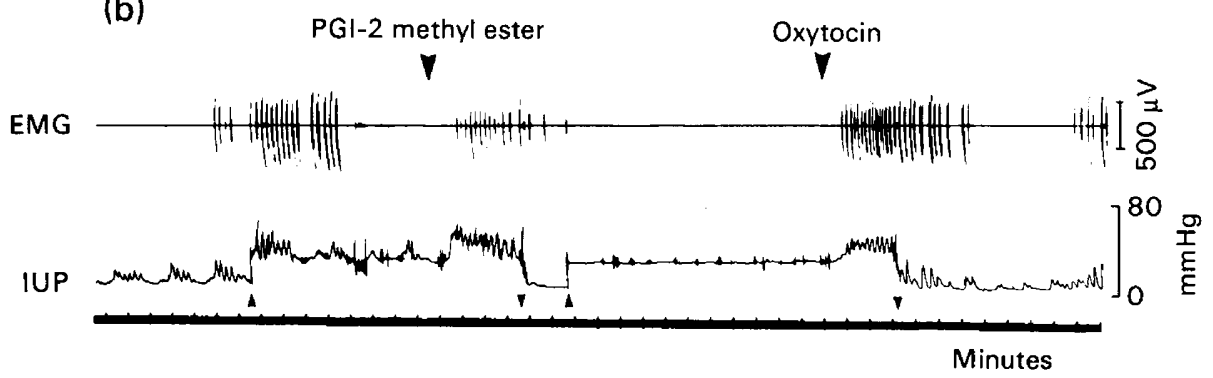

Text-fig. 3. Two traces of EMG and IUP for one sheep showing responses to (a) intra-arterial PGF- $2 \alpha(2 \mu \mathrm{g})$ and (b) intra-arterial oxytocin $(50 \mathrm{mU})$ after inhibition of spontaneous myometrial activity by $200 \mu \mathrm{g}$ PGI-2 methyl ester. PGF-2 $\alpha$ and oxytocin were administered 15 min after the PGI-2 when inhibition was maximal (see Text-fig. 2). Both agents produced stimulation of IUP and EMG activity. Small arrows indicate times when the animal stood $(\boldsymbol{\Delta})$ or lay down $(\boldsymbol{\nabla})$.

treatment with $200 \mu \mathrm{g}$ PGI-2 methyl ester and overcame, at least in part, the inhibitory action of the prostacyclin (Text-fig. 3). A similar response was seen in all 4 sheep.

\section{Discussion}

PGI-2 is a major prostaglandin of the human and ovine myometrium in pregnancy (Jones et al., 1977; Omini et al., 1979; Abel \& Kelly, 1979; Evans, Kennedy, Patrick \& Challis, 1981). Our results show a marked inhibitory action of PGI-2 on myometrial activity in vivo. This action is similar to the inhibitory effects of PGI-2 on human myometrial strips in vitro (Omini et al., 1978). It is striking that the onset of effect was equally rapid after the methyl ester and the salt, suggesting that the inhibitory action is unlikely to be due to the formation of a metabolite of PGI-2, although we cannot exclude this possibility. The concurrent inhibition of electrical as well as of mechanical activity might suggest that the PGI-2 action is primarily at the level of the myometrium rather than being mediated indirectly through changes in blood flow (Clark, Austin \& Stys, 1981).

We are unable to assess the physiological significance of the amounts of PGI-2 used in these studies, because the majority of the injected material would probably be diverted through the common iliac arteries, and we did not measure the proportion of the injected material that reached the uterus. However, our results raise the possibility that in some species, such as sheep and women, endogenous PGI-2 of uterine origin may be an inhibitor of myometrial activity in different states, including pregnancy. Our results suggest that such an inhibition might be overcome by oxytocin or PGF-2 $\alpha$ at term, either as the production of these agonists increases, or as a result of a change in uterine responsiveness (Thorburn \& Challis, 1979). 
This work was supported by the Medical Research Council of Canada (Group Grant in Reproductive Biology; Fellowship to S.J.L.). We thank Dr E. Masson (Upjohn Company, Toronto) for the gift of prostacyclin; and Ms C. Sprague, Dr D. Percy and Mr K. McGill for their assistance.

\section{References}

Abel, M.H. \& Kelly, R.W. (1979) Differential production of prostaglandins within the human uterus. Prostaglandins 18, 821-828.

Armstrong, J.M., Dusting, G.J., Moncada, S. \& Vane, J.R. (1978) Cardiovascular actions of prostacyclin $\left(\mathrm{PGI}_{2}\right)$, a metabolite of arachadonic acid which is synthesized by blood vessels. Circ. Res., Suppl. 1, 43, $112-119$.

Clark, K.E., Austin, J.E. \& Stys, S.J. (1981) Effect of bisenoic prostaglandins on the uterine vasculature of the non-pregnant sheep. Prostaglandins 22, 333348.

Evans, C.A., Kennedy, T.G., Patrick, J.E. \& Challis, J.R.G. (1981) Uterine prostaglandin concentrations in sheep during late pregnancy and adrenocorticotropin-induced labor. Endocrinology 109, 15331538.

Jones, R.L., Poyser, N.L. \& Wilson, N.H. (1977) Production of 6-oxo-prostaglandin Fla by rat, guinea-pig and sheep uteri in vitro. Br. J. Pharmac. $59,436-437$.

Lye, S.J. \& Porter, D.G. (1978) Demonstration that progesterone 'blocks' uterine activity in the ewe in vivo by a direct action on the myometrium. $J$. Reprod. Fert. 52, 87-94.

Manchester, E.L., Challis, J.R.G., MacLennan, E.A., Patrick, J.E. \& Workewych, J.V. (1980) A chronic fetal lamb preparation. Can. Ass. Lab. Anim. Sci. pp. 29-35.

Moncada, S., Gryglewski, R.J., Bunting, S. \& Vane, J.R. (1976) An enzyme isolated from arteries transforms prostaglandin endoperoxides to an unstable sub- stance that inhibits platelet aggregation. Nature, Lond. 263, 663-665.

Myatt, L. \& Elder, M.G. (1977) Inhibition of platelet aggregation by a placental substance with prostacyclin-like activity. Nature, Lond. 268, 159-160.

Omini, C., Pasargiklian, R., Folco, G.C., Fano, M. \& Berti, F. (1978) Pharmacological activity of $\mathrm{PGI}_{2}$ and its metabolite 6-oxo-PGF ${ }_{1 \alpha}$ on human uterus and fallopian tubes. Prostaglandins 15, 1045-1054.

Omini, C., Folco, G.C., Pasargiklian, R., Fano, M. \& Berti, F. (1979) Prostacyclin ( $\mathrm{PGI}_{2}$ ) in pregnant human uterus. Prostaglandins 17, 113-120.

Porter, D.G. (1979) The myometrium and the relaxin enigma. Anim. Reprod. Sci. 2, 77-96.

Satoh, K., Hasumizu, T., Kawai, Y., Ozaki, A., Wu, T., Kinoshita, K. \& Sakomoto, S. (1981) In vitro production of prostaglandin E, F and 6-keto-prostaglandin Fla by human pregnant uterus, decidua and amnion. Prostaglandins and Med. 6, 359-368.

Snedecor, G.W. (1956) Statistical Methods, 5th edn. Iowa State College Press, Ames.

Thorburn, G.D. \& Challis, J.R.G. (1979) Endocrinology of parturition. Physiol. Rev. 59, 863-918.

Williams, K.I., Dembinska-kiec, A., Zmuda, A. \& Gryglewski, R.J. (1978) Prostacyclin formation by myometrial and decidual fractions of the pregnant rat uterus. Prostaglandins 15, 343-350.

Williams, K.I., El-Tahir, K.E.H. \& Marcinkiewicz, E. (1979) Dual actions of prostacyclin $\left(\mathrm{PGI}_{2}\right)$ on the rat pregnant uterus. Prostaglandins 17, 667-672.

Received 30 December 1981 